\title{
Paraoxonase (PON1) and the risk for coronary heart disease and myocardial infarction in a general population of Dutch women
}

\author{
Thomas M. van Himbergen ${ }^{\text {a,c, }}{ }^{*}$, Yvonne T. van der Schouw ${ }^{b}$, \\ Hieronymus A.M. Voorbij ${ }^{\text {a }}$, Lambertus J.H. van Tits ${ }^{c}$, \\ Anton F.H. Stalenhoef ${ }^{\mathrm{c}}$, Petra H.M. Peeters ${ }^{\mathrm{b}}$, Mark Roest ${ }^{\mathrm{a}}$ \\ a Department of Clinical Chemistry and Haematology, University Medical Center Utrecht, Utrecht, The Netherlands \\ b Julius Center for Health Sciences and Primary Care, University Medical Center Utrecht, Utrecht, The Netherlands \\ ${ }^{\mathrm{c}}$ Department of Medicine, Division of General Internal Medicine, Radboud University Nijmegen Medical Center, Nijmegen, The Netherlands
}

Received 22 July 2007; received in revised form 2 November 2007; accepted 15 November 2007

Available online 27 December 2007

\begin{abstract}
There is strong evidence from both animal- and in vitro-models that paraoxonase (PON1) is involved in the onset of cardiovascular disease. In humans there is no consensus on this issue and therefore we investigated the effect of PON1 genotype and activity on the incidence of coronary heart disease (CHD) and acute myocardial infarction (AMI) in a large prospective cohort of 17,357 middle-aged women. We applied a case-cohort design using the CHD $(n=211)$ and AMI cases $(n=71)$ and a random sample from the baseline cohort $(n=1527)$. A weighted Cox proportional hazards model was used to estimate age- and multivariate-adjusted hazard ratios (HR) for the PON1 genetic variants (192Q $>\mathrm{R}$ and $-107 \mathrm{C}>\mathrm{T}$ ) and tertiles of the PON1 arylesterase- and paraoxonase activities. Neither the PON1 genetic variants, nor the PON1 activities affected the incidence of CHD in general, but, an increased paraoxonase activity was associated with a higher risk of AMI: the second and third tertile HR were 1.31 and 2.07, respectively ( $P$-trend $=0.029$, multivariate model). In the subgroup of never-smokers, paraoxonase activity was associated with an increased risk for AMI: the second and third tertile HR were 4.1 and 4.7 , respectively $(P$-trend $=0.009$, multivariate model). Additionally, when compared to the lowest paraoxonase tertile in never-smokers, the highest paraoxonase tertile in current-smokers showed a 19.2-fold higher risk for AMI (95\% CI: 5.3-69.5, $P<0.0001$, multivariate model). In conclusion, this study shows that in middle-aged women paraoxonase activity was associated with an increased risk for AMI and that the risk was modified by the effects of smoking.
\end{abstract}

(C) 2007 Elsevier Ireland Ltd. All rights reserved.

Keywords: Women; Myocardial infarction; Epidemiology; Paraoxonase; Smoking

\section{Introduction}

Serum paraoxonase (PON1) is a high-density lipoprotein (HDL)-associated enzyme which can hydrolyze lactones [1], and several non-physiological substrates, including arylesters and organophosphates [2,3]. Animal experimental work indicates that PON1 may be involved in atherogenesis:

\footnotetext{
* Corresponding author at: Lipid Metabolism Laboratory, Jean Mayer United States Department of Agriculture Human Nutrition Research Center on Aging at Tufts University, 711 Washington Street, Boston, MA 02111, USA.

E-mail address: thomas.vanhimbergen@tufts.edu (T.M. van Himbergen).
}

PON1-deficient mice are more prone to develop atherosclerosis than wild-type mice when fed a high-fat/high-cholesterol diet [4]. Several lines of evidence suggest that the PON1 involvement in atherogenesis is due to its ability to attenuate the oxidative modification of lipoprotein particles (reviewed in [5]), however, conclusive evidence remains to be delivered.

In vivo, there is a wide inter-individual variation in PON1 concentration and activity. This variation is for a major part determined by common genetic variants in the PON1 gene. A glutamine (Q)-to-arginine (R) transition at position 192 $(192 \mathrm{Q}>\mathrm{R})$ affects the PON1 hydrolytic activity towards paraoxon (paraoxonase activity), paraoxon is most efficiently hydrolyzed by the $192 \mathrm{R}$ isoform $[2,6]$. The $55 \mathrm{~L}>\mathrm{M}$ genetic variant in the coding region and the $-107 \mathrm{C}>\mathrm{T}$ genetic vari- 
ant in the promoter region of the enzyme affect the serum concentration of PON1, with the highest PON1 concentrations are found in individuals who are carrier of the 55LL and $-107 \mathrm{CC}$ genetic variants, respectively [7]. In order to biochemically characterize PON1, serum concentrations can be measured directly with an enzyme-linked immunosorbent assay (ELISA) [8], or estimated by monitoring the rate of hydrolysis toward phenylacetate (arylesterase activity) [9]. Together, the $192 \mathrm{Q}>\mathrm{R}, 55 \mathrm{~L}>\mathrm{M}$ and $-107 \mathrm{C}>\mathrm{T}$ polymorphisms are the bases for an up to 13-fold inter-individual variation in PON1 enzyme activity and concentration [10].

Epidemiological studies on the role of PON1 in cardiovascular disease have reported conflicting results (reviewed in [11]). A meta-analysis among 43 investigations demonstrated no effect for the 55L $>\mathrm{M}$ and $-107 \mathrm{C}>\mathrm{T}$ polymorphism and a slightly increased risk for carriers of the R-allele at position 192 for developing coronary heart disease (CHD) [12]. The main conclusion of this meta-analysis was to study the relation of PON1 genotype to CHD risk in large prospective populations. Furthermore, because PON1 is also influenced by lifestyle factors like smoking and alcohol consumption [13-15], it has been recommended to measure PON1 activity and concentration in addition to genotype [10,16-18]. Up to now, only two prospective investigations on PON1 activity and concentration and CHD outcome have been published, demonstrating either that low paraoxonase activity was an independent risk factor for coronary events [19], or no association between PON1 paraoxonase activity and CHD [20].

In the current study, we investigated the effects of PON1 genotypes, as well as paraoxonase- and arylesterase activity on the risk for developing CHD in a large prospective cohort of middle-aged women. We separately investigated the relation between PON1 and the occurrence of an acute myocardial infarction (AMI) as the most acute and serious clinical manifestation of CHD.

\section{Materials and methods}

\subsection{Population}

The study population consist of 17,357 postmenopausal women, aged between 49 and 70, who participated in the Prospect-EPIC study [21]. As previously described in detail, all women underwent a physical examination, filled out a questionnaire relating to lifestyle and medical factors, and donated a $30-\mathrm{mL}$ non-fasting blood sample at the time of recruitment [22]. Data on morbidity were obtained from the Dutch Centre for Health Care Information, which holds a standardized computerized register of hospital discharge diagnoses. All diagnoses were coded according to the International Classification of Diseases, ninth Revision (ICD-9). Using the ICD-9 codes, we categorized cardiovascular disease (ICD-9 390-459) as CHD (ICD-9 410-414) including AMI (ICD-9 410), the latter was also analyzed as a separate disease outcome. The diagnosis of CHD or AMI was the pri- mary reason for hospitalisation. Whenever multiple events occurred during follow-up, the first diagnosis was taken as endpoint. The database was linked to the cohort on the basis of birth date, gender, postal code, and general practitioner with a validated probabilistic method [23]. All women signed an informed consent form prior to study inclusion and the study was approved by the Institutional Review Board of the University Medical Center Utrecht.

\subsection{Design}

We selected all 303 first fatal and non-fatal CHD events that arose during follow-up until 1st January 2000. From the 17,357 women in the total cohort we randomly selected a sample of $10 \%(n=1736)$. Women who did not consent to linkage with vital status registries or who were not traceable were not included. Women who reported a diagnosis of cardiovascular disease (ICD-9; 390-459) at baseline, who had missing questionnaires or blood or DNA samples, or a daily energy intake below $500 \mathrm{kcal} /$ day were excluded from the analyses. For some women multiple reasons applied for exclusion resulting in a total number of 1527 women in the sub-cohort, that remained in the analyses and $211 \mathrm{CHD}$ cases of which 71 were AMI cases. For all case subjects follow up ended at the date of diagnosis or at the date of death due to cardiovascular disease.

\subsection{Laboratory measurements}

Biochemical measurements, including HDL and LDL cholesterol levels, were performed using standard laboratory procedures [22]. Serum PON1 enzyme activities towards paraoxon and phenylacetate and the PON1 - 107CT, 55L > M and $192 \mathrm{Q}>\mathrm{R}$ genotypes were determined by methods previously described [24].

\subsection{Statistical analyses}

Baseline variables were tested for a normal distribution and comparisons among the random cohort and disease outcome were performed using the two-sample $T$-test for normal distributed continuous variables, the Mann-Whitney test for non-normal distributed continuous variables and the $\chi^{2}$ test for categorical variables. The $\chi^{2}$ test was used both to test if genotype frequencies deviated from Hardy-Weinberg equilibrium expectations and to evaluate the significance of the linkage disequilibrium between the two polymorphisms.

The hazard ratios (HR) for PON1 genotype, paraoxonaseand arylesterase activity with CHD and AMI were evaluated in Cox-proportional-hazard models with an estimation procedure adapted for case-cohort designs according to unweighted method by Prentice [25], using the SAS macro written by Barlow et al. [26]. Results were summarized as HR with $95 \%$ confidence intervals $(95 \% \mathrm{CI})$. In the model, the common genetic variants -107CC and 192QQ served as reference category. As for the PON1 activity, paraoxonase- 
Table 1

Baseline characteristics

\begin{tabular}{|c|c|c|c|c|c|}
\hline Variable & $\begin{array}{l}\text { Random cohort, } \\
n=1527\end{array}$ & $\begin{array}{l}\text { Coronary heart } \\
\text { disease, } n=211\end{array}$ & $\begin{array}{l}\text { Acute myocardial } \\
\text { infarction, } n=71\end{array}$ & $P$-value* & $P$-value $†$ \\
\hline Age (years) & $57 \pm 6$ & $61 \pm 6$ & $62 \pm 6$ & $<0.001$ & $<0.001$ \\
\hline Body mass index $\left(\mathrm{kg} / \mathrm{m}^{2}\right)$ & $25.8 \pm 3.9$ & $26.8 \pm 3.9$ & $26.4 \pm 4.0$ & 0.001 & 0.245 \\
\hline Systolic blood pressure $(\mathrm{mm} \mathrm{Hg})$ & $133 \pm 20$ & $143 \pm 22$ & $146 \pm 25$ & $<0.001$ & $<0.001$ \\
\hline Diastolic blood pressure ( $\mathrm{mm} \mathrm{Hg}$ ) & $79 \pm 11$ & $82 \pm 11$ & $84 \pm 13$ & 0.001 & $<0.001$ \\
\hline LDL cholesterol (mmol/L) & $3.9 \pm 0.9$ & $4.4 \pm 1.0$ & $4.4 \pm 1.0$ & $<0.001$ & $<0.001$ \\
\hline HDL cholesterol (mmol/L) & $1.6 \pm 0.4$ & $1.4 \pm 0.3$ & $1.4 \pm 0.4$ & $<0.001$ & 0.001 \\
\hline Smoking, current/past/never & $351 / 529 / 652$ & $72 / 55 / 84$ & $32 / 16 / 23$ & $<0.001$ & $<0.001$ \\
\hline Alcohol consumption (g/day) & $3.9(0.4-14.1)$ & $1.4(0.03-9.5)$ & $1.7(0.03-8.2)$ & $<0.001$ & 0.004 \\
\hline Paraoxonase activity (U/L) & $114(62-240)$ & $115(64-211)$ & $152(73-235)$ & 0.466 & 0.241 \\
\hline Arylesterase activity (U/mL) & $87 \pm 25$ & $82 \pm 23$ & $83 \pm 24$ & 0.005 & 0.144 \\
\hline
\end{tabular}

Age, body mass index, systolic blood pressure, diastolic blood pressure, LDL cholesterol, HDL cholesterol and PON1 arylesterase activity are reported as means \pm S.D. Alcohol consumption and paraoxonase activity are presented as median values and the interquartile range. *For the comparison of the coronary heart disease cases with the random cohort. †For the comparison of the acute myocardial infarction cases with the random cohort.

Table 2

Distribution HDL cholesterol and PON1 paraoxonase and arylesterase activities among PON1 $-107 \mathrm{C}>\mathrm{T}, 55 \mathrm{~L}>\mathrm{M}$ and 192Q $>\mathrm{R}$ genotypes in the random cohort $(n=1527)$

\begin{tabular}{|c|c|c|c|c|c|c|c|c|c|}
\hline & \multicolumn{3}{|l|}{$-107 \mathrm{C}>\mathrm{T}$} & \multicolumn{3}{|l|}{$55 \mathrm{~L}>\mathrm{M}$} & \multicolumn{3}{|l|}{$192 \mathrm{Q}>\mathrm{R}$} \\
\hline & $\mathrm{CC}$ & $\mathrm{CT}$ & $\mathrm{TT}$ & LL & LM & $\mathrm{MM}$ & QQ & QR & RR \\
\hline $\begin{array}{l}\text { Number of } \\
\text { subjects }\end{array}$ & 412 & 752 & 341 & 601 & 703 & 210 & 785 & 589 & 140 \\
\hline $\begin{array}{l}\text { HDL } \\
\text { cholesterol } \\
(\mathrm{mmol} / \mathrm{L})\end{array}$ & $1.6 \pm 0.4$ & $1.6 \pm 0.4$ & $1.6 \pm 0.4$ & $1.6 \pm 0.4$ & $1.6 \pm 0.4$ & $1.6 \pm 0.4$ & $1.6 \pm 0.4$ & $1.6 \pm 0.4$ & $1.6 \pm 0.4$ \\
\hline $\begin{array}{l}\text { Paraoxonase } \\
\text { activity (U/L) }\end{array}$ & $206(85-291)$ & $102(63-237)$ & $71(40-156)^{*}$ & $214(98-309)$ & $92(58-208)$ & $47(30-70)^{*}$ & $65(46-84)$ & $224(170-267)$ & $382(316-460)^{*}$ \\
\hline $\begin{array}{l}\text { Arylesterase } \\
\text { activity }(\mathrm{U} / \mathrm{mL})\end{array}$ & $104 \pm 22$ & $86 \pm 21$ & $68 \pm 21^{*}$ & $98 \pm 23$ & $83 \pm 22$ & $70 \pm 23^{*}$ & $84 \pm 24$ & $89 \pm 25$ & $94 \pm 25^{*}$ \\
\hline
\end{tabular}

HDL cholesterol and arylesterase are reported as means \pm S.D. Paraoxonase activity is presented as the median value and the interquartile range. ${ }^{*} P$-trend $<0.001$.

and arylesterase activity were divided in to tertiles, where the lowest activity tertile was used as the reference group. The models were adjusted for age and HDL-cholesterol, smoking status and alcohol consumption. In the test for trend analysis ( $P$-trend), the $-107 \mathrm{C}>\mathrm{T}, 55 \mathrm{~L}>\mathrm{M}$ and 192Q $>\mathrm{R}$ polymorphisms and the tertiles of paraoxonase activity were added to the model as a continuous variable. Because smoking status strongly predicted AMI incidence, we also investigated the effects of paraoxonase activity on AMI incidence in subgroups of current-smokers, past-smokers and never-smokers, controlling for age, HDL-cholesterol and alcohol consumption.

All statistical analyses were performed using SAS version 9.1.

\section{Results}

Table 1 shows the baseline characteristics of the random cohort, the CHD and the AMI cases. When compared with the random cohort, the $\mathrm{CHD}$ and the AMI cases were older, had higher blood pressures and higher levels of LDL-cholesterol and lower levels of HDL-cholesterol. The body mass index was only significantly higher in the CHD cases. There was a graded increase for the percentage of smokers with the severity of CHD (23\% in the random cohort, $34 \%$ in the CHD cases and $45 \%$ in the AMI cases), and the consumption of alcohol was lower in both the CHD and AMI cased. Finally, paraoxonase activity was increased in the AMI cases and arylesterase activity was significantly lower in the CHD cases, when compared to the random cohort.

Table 3

Coronary heart disease and acute myocardial infarction hazard ratios (with $95 \%$ confidence intervals) by $\mathrm{PON} 1-107 \mathrm{C}>\mathrm{T}, 55 \mathrm{~L}>\mathrm{M}$ and $192 \mathrm{Q}>\mathrm{R}$ genotype

\begin{tabular}{cll}
\hline & $\begin{array}{l}\text { Coronary heart disease } \\
\text { hazard ratios }(95 \% \mathrm{CI})\end{array}$ & $\begin{array}{l}\text { Acute myocardial infarction } \\
\text { hazard ratios }(95 \% \mathrm{CI})\end{array}$ \\
\hline$-107 \mathrm{C}>\mathrm{T}$ & & 1.00 (reference) \\
$\mathrm{CC}$ & 1.00 (reference) & $0.97(0.56-1.69)$ \\
$\mathrm{CT}$ & $0.93(0.66-1.31)$ & $0.67(0.32-1.39)$ \\
TT & $0.79(0.51-1.20)$ & 1.00 (reference) \\
$55 \mathrm{~L}>\mathrm{M}$ & & $0.86(0.51-1.44)$ \\
LL & $1.00($ reference) & $0.62(0.27-1.41)$ \\
LM & $0.93(0.68-1.29)$ & \\
MM & $0.76(0.47-1.22)$ & $1.00($ reference) \\
$192 \mathrm{Q}>\mathrm{R}$ & & $1.39(0.83-2.32)$ \\
QQ & $1.00($ reference) & $1.37(0.59-3.21)$ \\
QR & $1.06(0.78-1.44)$ & \\
RR & $0.78(0.43-1.42)$ &
\end{tabular}

Hazard models were adjusted for age. 
Table 4

Coronary heart disease and acute myocardial infarction hazard ratios (with 95\% confidence intervals) by tertiles of paraoxonase- and arylesterase activity

\begin{tabular}{|c|c|c|c|c|c|c|}
\hline & \multicolumn{3}{|c|}{ Coronary heart disease hazard ratios $(95 \% \mathrm{CI})$} & \multicolumn{3}{|c|}{ Acute myocardial infarction hazard ratios $(95 \% \mathrm{CI})$} \\
\hline & Model 1 & Model 2 & Model 3 & Model 1 & Model 2 & Model 3 \\
\hline \multicolumn{7}{|c|}{ Paraoxonase activity } \\
\hline$<73(\mathrm{U} / \mathrm{L})$ & 1.00 (reference) & 1.00 (reference) & 1.00 (reference) & 1.00 (reference) & 1.00 (reference) & 1.00 (reference) \\
\hline 73-204 (U/L) & $1.08(0.76-1.54)$ & $1.10(0.77-1.56)$ & $1.07(0.75-1.55)$ & $1.34(0.71-2.54)$ & $1.34(0.71-2.53)$ & $1.31(0.69-2.50)$ \\
\hline >204 (U/L) & $1.04(0.72-1.50)$ & $1.14(0.78-1.65)$ & $1.18(0.80-1.72)$ & $1.74(0.94-3.24)^{*}$ & $1.88(1.01-3.50)^{\dagger, \ddagger}$ & $2.07(1.11-3.84)^{\S, \|}$ \\
\hline \multicolumn{7}{|c|}{ Arylesterase activity } \\
\hline$<76(\mathrm{U} / \mathrm{mL})$ & 1.00 (reference) & 1.00 (reference) & 1.00 (reference) & 1.00 (reference) & 1.00 (reference) & 1.00 (reference) \\
\hline 76-97 (U/mL) & $0.98(0.70-1.38)$ & $1.08(0.76-1.52)$ & $1.07(0.75-1.51)$ & $0.87(0.49-1.54)$ & $0.92(0.51-1.64)$ & $0.91(0.50-1.64)$ \\
\hline$>97(\mathrm{U} / \mathrm{mL})$ & $0.74(0.50-1.08)^{\top}$ & $0.90(0.60-1.34)$ & $1.01(0.67-1.51)$ & $0.85(0.46-1.56)$ & $0.92(0.49-1.74)$ & $1.17(0.62-2.19)$ \\
\hline
\end{tabular}

Model 1 was adjusted for age, model 2 was adjusted for age and HDL-cholesterol and model 3 was adjusted for age, HDL-cholesterol, smoking status and alcohol consumption. ${ }^{*} P$-trend $=0.062,{ }^{\dagger} P=0.046$ when compared to the reference group, ${ }^{\ddagger} P$-trend $=0.045,{ }^{\S} P=0.022$ when compared to the reference group, ${ }^{\|} P$-trend $=0.029,{ }^{\top} P$-trend $=0.107$.

In the random cohort, the distribution of the $192 \mathrm{Q}>\mathrm{R}$, $55 \mathrm{~L}>\mathrm{M}$ and $-107 \mathrm{C}>\mathrm{T}$ polymorphisms did not deviate from the Hardy-Weinberg equilibrium. Furthermore, there was significant linkage disequilibrium between these polymorphisms $\left(\chi^{2} P\right.$-value $\left.<0.001\right)$. HDL-cholesterol levels and the PON1 activities among PON1 genotypes in the random cohort are shown in Table 2. No differences in HDL-cholesterol levels were observed among the 192Q $>$ R, $55 \mathrm{~L}>\mathrm{M}$ and $-107 \mathrm{C}>\mathrm{T}$ polymorphisms. There was an evident relationship between the PON1 genotypes and the PON1 activity measurements. The $-107 \mathrm{C}>\mathrm{T}$ and $55 \mathrm{~L}>\mathrm{M}$ polymorphisms had the strongest influence on the arylesterase activity, with the highest arylesterase activity found in individuals with the $-107 \mathrm{CC}$ or the 55LL genotype. The $192 \mathrm{Q}>\mathrm{R}$ polymorphism had the strongest influence on the paraoxon hydrolysis, with the highest paraoxon hydrolytic activity found in carriers of the 192RR genetic variant. There was also an association of the $192 \mathrm{Q}>\mathrm{R}$ polymorphism with the arylesterase activity $(P$-trend $<0.001)$, and the $-107 \mathrm{C}>\mathrm{T}$ and $55 \mathrm{~L}>\mathrm{M}$ polymorphisms with the paraoxonase activity $(P$-trend $<0.001)$.

Table 3 shows the relationship of the PON1 genetic variants $-107 \mathrm{C}>\mathrm{T}, 55 \mathrm{~L}>\mathrm{M}$ and 192Q $>\mathrm{R}$ with the HR for CHD and AMI. Overall, the effects of these genotypes on CHD and AMI incidence were too weak to draw conclusions.

The hazard ratios for tertiles of paraoxonase- and arylesterase activity to develop CHD or AMI are presented in Table 4. Although not reaching statistical significance, the increased arylesterase activity tended to associate with a lower incidence of CHD in the age-adjusted model (second and third tertile HR: 0.98 and $0.74, P$-trend $=0.107$ ). This effect, however, declined in the multivariate-adjusted models. In general, there was no apparent effect of PON1 paraoxonase- and arylesterase activity on the incidence of CHD. When investigating the role of PON1 on the incidence of AMI, paraoxonase activity tended to associate with a higher incidence of AMI in the age-adjusted model, hazard ratios for the second and third tertile were 1.34 and 1.74 , respectively $(P$-trend $=0.062)$. The strength of the association of paraoxonase activity with AMI became stronger after additional adjustments for HDL-cholesterol, smoking status and alcohol consumption, with the highest tertile significantly associated with a twofold increased incidence of AMI (HR: 2.07, 95\%CI: $1.11-3.84, P=0.022$ ).

In this study, menopausal status or the use of hormone replacement therapy did not have an effect on the PON1 activities (data not shown). Smoking status, however, did effect the PON1's activities: in the random cohort, paraoxonase and arylesterase activities were lower in smokers when compared to people who have never smoked (paraoxonase: $152 \mathrm{U} / \mathrm{L}$ versus $163 \mathrm{U} / \mathrm{L}$, age-adjusted $P$-difference $=0.12$. Arylesterase: $84 \mathrm{U} / \mathrm{mL}$ versus $88 \mathrm{U} / \mathrm{mL}$, age-adjusted $P$ difference $=0.006$ ). The combined effects of smoking and paraoxonase activity on AMI incidence adjusted for age, HDL-cholesterol and alcohol are presented in Fig. 1. In people who have never smoked, increased paraoxonase activity was an AMI risk factor: the second and third tertile of paraoxonase activity HR were 4.1 (95\%CI: 0.9-18.5,

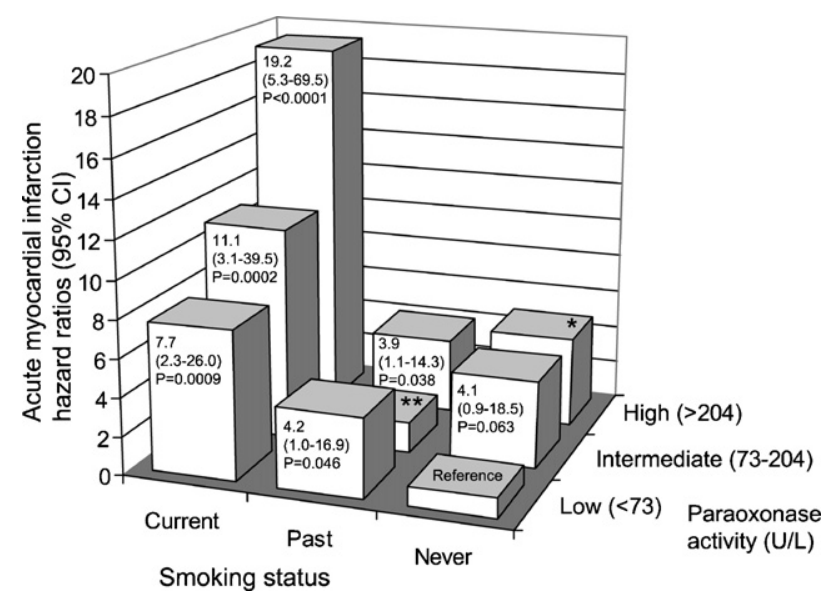

Fig. 1. Combined effects of paraoxonase activity (in tertiles) and smoking status (current-, past- and never-smoking) on the incidence of AMI. The hazard ratios (HR) and $95 \%$ confidence intervals $(95 \% \mathrm{CI})$ are displayed in the bars and represent the comparison with the low paraoxonase/nonsmoking reference group. HR are controlled for age, HDL-cholesterol and alcohol consumption. *HR: 4.7 (1.2-18.5), $P=0.026$. **HR: $1.6(0.4-7.0)$, $P=0.532$. 
$P=0.063)$ and 4.7 (95\%CI: $1.2-18.5, P=0.026)$, respectively $(P$-trend $=0.009)$. In addition, the high-paraoxonase/currentsmokers subgroup had a 19.2-fold increased risk for AMI incidence (95\% CI: 5.3-69.5, $P<0.0001$ ) when compared to the low-paraoxonase/never-smokers subgroup. On the other hand, the effects of paraoxonase activity on AMI outcome did not reach statistical significant when considered in a subgroup of smokers (HR 1.4, 95\%CI: $0.5-3.7, P=0.47$, for the high paraoxonase activity tertile versus the low paraoxonase activity tertile. Data not shown).

\section{Discussion}

In this cohort of women, we found no evidence for a relationship between PON1 genetic variants, PON1 activity and CHD in general, or between the PON1 genetic variants and AMI. Increased paraoxonase activity, however, was an AMI risk factor. In addition, when the highest paraoxonase activity tertile in current-smokers was compared to the lowest paraoxonase activity tertile in never-smokers, the combined effects of paraoxonase activity with smoking status predicted a more than 19-fold increased risk for AMI incidence.

In order to place our findings into perspective, it is important to realize that paraoxon is most efficiently hydrolyzed by the PON1-192RR genetic variant [2,3]. Previous studied on the role of the 192Q $>\mathrm{R}$ genetic variant have demonstrated that the PON1Q allozyme possesses a greater ability than PON1R allozyme in protecting LDL from oxidation $[27,28]$, and that the PON1Q variant was more potent than the PON1R variant in reducing oxidized lipids in human atherosclerotic lesions [29]. Based on these findings one can hypothesize that the PON1 192RR is the less favorable genetic variant for the risk for developing cardiovascular disease. Many studies on the effects of the 192Q $>$ R polymorphism and cardiovascular disease have been performed during the recent years and as indicated by a meta-analysis among 43 studies involving a total of 11212 CHD cases and 12786 controls, subjects with the 192R-allele have a significant 1.12-fold increased risk for CHD [12]. While it is questionable whether this slight increase in relative risk found for the 192R-allele has a relevant impact on CHD, it does support our recent finding, that elevated paraoxonase activity (caused by the 192R variant) at baseline predicted an increased risk to develop AMI.

Although PON1 can hydrolyze a wide range of substrates, it should be borne in mind that recent studies have demonstrated that PON1 is in fact a lactonase, catalyzing both the hydrolysis and the formation of a number of lactones $[1,30,31]$. The PON1 paraoxonase activity is a poor reflection of PON1 native activity and its in vivo role remains largely unclear. Arylesterase activity, on the other hand, is mediated by the same His ${ }^{115}$-His ${ }^{134}$ dyad which is responsible for PON1's native lactonase activity [32], and is thought to be a better reflection of PON1 anti-oxidative potential. Interestingly, we find that baseline arylesterase activity is significantly lower in CHD cases and tend to be lower in AMI cases when compared to the random cohort. However, since this relationship did not reach statistical significance in the multivariate model, it is questionable whether arylesterase activity plays a biologically relevant role in the onset of CHD.

Relative to the number of PON1 genetic studies on the onset of cardiovascular disease, there have been a few case-control studies that have included a quantification of PON1 activity and concentration (reviewed in [17]) and studies on a direct relationship between PON1 paraoxonase activity and the incidence of cardiovascular disease are scarce $[19,20]$. Before drawing firm conclusions from case-control studies, it must be stressed that a major limitation of the case-control study design is that blood is drawn after the cardiovascular event has taken place. One cannot distinguish whether PON1 activity contributed to the manifestation of the event or, conversely, the event itself influenced the PON1 activity. To overcome this problem a prospective study design is needed. Our study is the third prospective investigation on the effects of PON1 activity and concentration to cardiovascular endpoints. Previously, prospective investigations on PON1 in relation to cardiovascular disease risk were performed in the Caerphilly study [19], and very recently in the PRIME study [20]. Mackness et al. reported in the Caerphilly study that low serum PON1 activity toward paraoxon was an independent risk factor for coronary events in men with preexisting CHD, while no relationship was observed in men without preexisting CHD [19]. They did not observe any increased risk associated with PON1 concentration. The PRIME study, a multi center prospective investigation in 10,593 middle-aged men, reported no effect of PON1 paraoxonase activity or the $55 \mathrm{~L}>\mathrm{M}$ genotype on CHD outcome. The PRIME study did not investigate the effects of a PON1 concentration measure in relation to cardiovascular disease risk. In the current study, we observed a non-significant trend for PON1 concentration (arylesterase activity) and CHD outcome. Conversely, it was remarkable that elevated paraoxonase activity was a risk factor for AMI. Although the PRIME study did not find any effect for paraoxonase activity, our observation that increased paraoxonase activity is a risk factor for cardiovascular outcomes instead of being protective, seems to be in conflict with the findings of Mackness et al. in the men with preexisting CHD. There are, however, some essential differences between the Caerphilly study and the current study which may account for the variation in study outcome. (1) The Caerphilly study was limited to men, while our study was restricted to women. A recent study among a general population showed that PON1 activity may be different between men and in women [33]. Furthermore, PON1-gender interactions have been reported in relation to clinical outcome [34]. (2) The participants of the Caerphilly study were in the fasting state when blood was donated, while the current study used non-fasting blood samples. There is evidence that PON1 activities are lower in the postprandial state when compared to the fasting state [35]. (3) The Caerphilly study observed effects in a subgroup of men with preexisting CHD, while we have excluded all women 
with preexisting CHD at baseline. PON1 levels and/or activity may diminish after an inflammatory acute phase response, as seen in animals and humans [36-39], raising the possibility that in the Caerphilly study the PON1 status may have been altered due to a previous CHD event. Therefore, when comparing the two studies, it cannot be excluded that gender differences and/or differences due to prandial and inflammatory status may have influenced the effect of PON1 on the CHD outcome. Overall, the results of the three prospective investigations do not provide convincing evidence that PON1 paraoxonase activity is a strong risk factor for CHD in the general population. Furthermore, based on subgroups of men with preexisting CHD and AMI cases no univocal conclusions can be drawn regarding paraoxonase activity and therefore further prospective investigations are needed to understand these apparently contradictory results.

In this study, paraoxonase activity was a risk factor for AMI only and not for CHD in general. CHD is an umbrellaterm covering different stages of (chronic stable and acute) heart problems. One of the first steps in atherogenesis is the formation of a lipid-rich plaque, which forms the basis for all forms of CHD [40]. At a later stage in the atherosclerotic process, the physiological disruption of the atherosclerotic plaque and, as a result, the formation of a thrombotic occlusion, causes the most acute and serious clinical manifestations of CHD, i.e. AMI [41]. Our findings that paraoxonase was a risk factor for AMI, suggest that PON1 may be of importance in the later stages of atherosclerosis. This does not only warrant further investigation on the role of PON1 in plaque instability and thrombosis, but also suggests that important effects of PON1 will be missed when all forms of CHD are grouped as a common CHD outcome.

Many population studies have shown that smoking is a major risk-factor for cardiovascular disease and accordingly, we found that the percentage of smokers was higher among people who developed an AMI. With regard to PON1, in our study the PON1 activities were lower due to the effects of smoking. As a result, there was a significant relationship between PON1 and AMI in people who have never smoked and while a trend was observed in smokers this relationship did not reach statistical significance. These data suggest that smoking, to some extent, reduces the harmful effects of high paraoxonase activity which leads to an increased risk for developing an AMI. Reconciling these apparently contradictory results it must be stressed that the risk for AMI incidence was strikingly higher for the combination of high-paraoxonase/current-smokers when compared to low-paraoxonase/never-smokers. And although these findings must be viewed with some reservedness since they were based on a small number of cases per subgroup, they do underline the importance of stratifying for smoking status when investigating the effect of PON1 on cardiovascular disease.

Previously, we found an association between PON1 genotypes and HDL-cholesterol levels in patients with familial hypercholesterolemia and hypothesized that PON1 enhances the function of the HDL particle [42]. In this general popu- lation of women, we observed a positive correlation for both arylesterase- and paraoxonase activity with HDL-cholesterol levels, however, the strength of the association of paraoxonase activity with the incidence of AMI was only marginally affected by adjustments for HDL-cholesterol levels. These findings suggest that the mechanism by which paraoxonase activity forms a risk factor for AMI incidence was not primarily via an interaction with the function of the HDL-cholesterol particle. It must be noted that the exact physiological function of PON1 is still unclear, but the anti-oxidative properties of PON1 [43], and a secondary inflammatory response [44], may alternatively be important parameters for the occurrence of AMI.

Finally, we will address the strengths and weaknesses of our investigation. We were aware that the small number of CHD cases was a limitation to our study. At the time of investigation, there were only 211 cases of CHD (of which 71 cases of AMI) in the total cohort of 17,357 women, and it can be expected that more events will occur during a longer period of follow-up. Nevertheless, our prospective study design was still highly favorable over findings from case-control studies, because we could be sure that the effects of PON1 preceded the onset of CHD, and so, we could assess a causal role of PON1 in this process.

In conclusion, several animal models and in vitro studies have suggested a protective function of PON1 against the onset of cardiovascular disease. On the other hand, we demonstrated that PON1's paraoxonase activity was a risk factor for the incidence of AMI and that this risk was modified in smokers. Future (prospective) investigations are needed to confirm this hypothesis.

\section{Acknowledgments}

This study was financially supported by the Netherlands Heart Foundation (Research Grant \#2001.038). The authors thank J.H. van Kats-Renaud and A.D. Barendrecht for technical assistance.

\section{References}

[1] Draganov DI, Teiber JF, Speelman A, Osawa Y, Sunahara R, La Du BN. Human paraoxonases (PON1, PON2, and PON3) are lactonases with overlapping and distinct substrate specificities. J Lipid Res 2005;46:1239-47.

[2] Humbert R, Adler DA, Disteche CM, Hassett C, Omiecinski CJ, Furlong $\mathrm{CE}$. The molecular basis of the human serum paraoxonase activity polymorphism. Nat Genet 1993;3:73-6.

[3] Davies HG, Richter RJ, Keifer M, Broomfield CA, Sowalla J, Furlong CE. The effect of the human serum paraoxonase polymorphism is reversed with diazoxon, soman and sarin. Nat Genet 1996;14:334-6.

[4] Shih DM, Gu L, Xia YR, et al. Mice lacking serum paraoxonase are susceptible to organophosphate toxicity and atherosclerosis. Nature 1998;394:284-7.

[5] Ng CJ, Shih DM, Hama SY, Villa N, Navab M, Reddy ST. The paraoxonase gene family and atherosclerosis. Free Radic Biol Med 2005;38:153-63. 
[6] Adkins S, Gan KN, Mody M, La Du BN. Molecular basis for the polymorphic forms of human serum paraoxonase/arylesterase: glutamine or arginine at position 191, for the respective A or B allozymes. Am J Hum Genet 1993;52:598-608.

[7] Brophy VH, Jampsa RL, Clendenning JB, McKinstry LA, Jarvik GP, Furlong CE. Effects of $5^{\prime}$ regulatory-region polymorphisms on paraoxonase-gene (PON1) expression. Am J Hum Genet 2001;68:1428-36.

[8] Kujiraoka T, Oka T, Ishihara M, et al. A sandwich enzyme-linked immunosorbent assay for human serum paraoxonase concentration. J Lipid Res 2000;41:1358-63.

[9] Eckerson HW, Wyte CM, La Du BN. The human serum paraoxonase/arylesterase polymorphism. Am J Hum Genet 1983;35:1126-38.

[10] Richter RJ, Furlong CE. Determination of paraoxonase (PON1) status requires more than genotyping. Pharmacogenetics 1999;9:745-53.

[11] Costa LG, Cole TB, Jarvik GP, Furlong CE. Functional genomic of the paraoxonase (PON1) polymorphisms: effects on pesticide sensitivity, cardiovascular disease, and drug metabolism. Annu Rev Med 2003;54:371-92.

[12] Wheeler JG, Keavney BD, Watkins H, Collins R, Danesh J. Four paraoxonase gene polymorphisms in 11212 cases of coronary heart disease and 12786 controls: meta-analysis of 43 studies. Lancet 2004;363:689-95.

[13] Nishio E, Watanabe Y. Cigarette smoke extract inhibits plasma paraoxonase activity by modification of the enzyme's free thiols. Biochem Biophys Res Commun 1997;236:289-93.

[14] James RW, Leviev I, Righetti A. Smoking is associated with reduced serum paraoxonase activity and concentration in patients with coronary artery disease. Circulation 2000;101:2252-7.

[15] van der Gaag MS, van Tol A, Scheek LM, et al. Daily moderate alcohol consumption increases serum paraoxonase activity; a diet-controlled, randomised intervention study in middle-aged men. Atherosclerosis 1999; 147:405-10.

[16] Mackness B, Davies GK, Turkie W, et al. Paraoxonase status in coronary heart disease: are activity and concentration more important than genotype? Arterioscler Thromb Vasc Biol 2001;21:1451-7.

[17] Mackness M, Mackness B. Paraoxonase 1 and atherosclerosis: is the gene or the protein more important? Free Radic Biol Med 2004;37:1317-23.

[18] Jarvik GP, Rozek LS, Brophy VH, et al. Paraoxonase (PON1) phenotype is a better predictor of vascular disease than is PON1(192) or PON1(55) genotype. Arterioscler Thromb Vasc Biol 2000;20: 2441-7.

[19] Mackness B, Durrington P, McElduff P, et al. Low paraoxonase activity predicts coronary events in the Caerphilly prospective study. Circulation 2003;107:2775-9.

[20] Troughton JA, Woodside JV, Yarnell JW, et al. Paraoxonase activity and coronary heart disease risk in healthy middle-aged males: the PRIME study. Atherosclerosis 2007.

[21] Boker LK, van Noord PA, van der Schouw YT, et al. Prospect-EPIC Utrecht: study design and characteristics of the cohort population. European prospective investigation into cancer and nutrition. Eur $\mathrm{J}$ Epidemiol 2001;17:1047-53.

[22] van der AD, Marx JJ, Grobbee DE, et al. Non-transferrin-bound iron and risk of coronary heart disease in postmenopausal women. Circulation 2006;113:1942-9.

[23] Herings RM, Bakker A, Stricker BH, Nap G. Pharmaco-morbidity linkage: a feasibility study comparing morbidity in two pharmacy based exposure cohorts. J Epidemiol Community Health 1992;46:13640.

[24] Roest M, van Himbergen TM, Barendrecht AB, Peeters PH, van der Schouw YT, Voorbij HA. Genetic and environmental determinants of the PON-1 phenotype. Eur J Clin Invest 2007;37:187-96.
[25] Prentice RL. A case-cohort design for epidemiologic cohort studies and disease prevention trials. Biometrika 1986;73:1-11.

[26] Barlow WE, Ichikawa L, Rosner D, Izumi S. Analysis of case-cohort designs. J Clin Epidemiol 1999;52:1165-72.

[27] Aviram M, Billecke S, Sorenson R, et al. Paraoxonase active site required for protection against LDL oxidation involves its free sulfhydryl group and is different from that required for its arylesterase/paraoxonase activities: selective action of human paraoxonase allozymes Q and R. Arterioscler Thromb Vasc Biol 1998;18:1617-24.

[28] Mackness B, Mackness MI, Arrol S, Turkie W, Durrington PN. Effect of the human serum paraoxonase 55 and 192 genetic polymorphisms on the protection by high density lipoprotein against low density lipoprotein oxidative modification. FEBS Lett 1998;423:57-60.

[29] Aviram M, Hardak E, Vaya J, et al. Human serum paraoxonases (PON1) Q and R selectively decrease lipid peroxides in human coronary and carotid atherosclerotic lesions: PON1 esterase and peroxidase-like activities. Circulation 2000;101:2510-7.

[30] Khersonsky O, Tawfik DS. Structure-reactivity studies of serum paraoxonase PON1 suggest that its native activity is lactonase. Biochemistry 2005;44:6371-82.

[31] Harel M, Aharoni A, Gaidukov L, et al. Structure and evolution of the serum paraoxonase family of detoxifying and anti-atherosclerotic enzymes. Nat Struct Mol Biol 2004;11:412-9.

[32] Khersonsky O, Tawfik DS. The histidine 115-histidine 134 dyad mediates the lactonase activity of mammalian serum paraoxonases. J Biol Chem 2006;281:7649-56.

[33] Ferre N, Camps J, Fernandez-Ballart J, et al. Regulation of serum paraoxonase activity by genetic, nutritional, and lifestyle factors in the general population. Clin Chem 2003;49:1491-7.

[34] Rios DL, D'Onofrio LO, Cerqueira CC, et al. Paraoxonase 1 gene polymorphisms in angiographically assessed coronary artery disease: evidence for gender interaction among Brazilians. Clin Chem Lab Med 2007; 45:874-8

[35] Beer S, Moren X, Ruiz J, James RW. Postprandial modulation of serum paraoxonase activity and concentration in diabetic and non-diabetic subjects. Nutr Metab Cardiovasc Dis 2006;16:457-65.

[36] Cabana VG, Reardon CA, Feng N, Neath S, Lukens J, Getz GS. Serum paraoxonase: effect of the apolipoprotein composition of HDL and the acute phase response. J Lipid Res 2003;44:780-92.

[37] Feingold KR, Memon RA, Moser AH, Grunfeld C. Paraoxonase activity in the serum and hepatic mRNA levels decrease during the acute phase response. Atherosclerosis 1998;139:307-15.

[38] Van Lenten BJ, Wagner AC, Nayak DP, Hama S, Navab M, Fogelman AM. High-density lipoprotein loses its anti-inflammatory properties during acute influenza a infection. Circulation 2001;103:2283-8.

[39] Van Lenten BJ, Hama SY, de Beer FC, et al. Anti-inflammatory HDL becomes pro-inflammatory during the acute phase response. Loss of protective effect of HDL against LDL oxidation in aortic wall cell cocultures. J Clin Invest 1995;96:2758-67.

[40] Steinberg D. Atherogenesis in perspective: hypercholesterolemia and inflammation as partners in crime. Nat Med 2002;8:1211-7.

[41] Shah PK. Mechanisms of plaque vulnerability and rupture. J Am Coll Cardiol 2003;41:15S-22S.

[42] van Himbergen TM, Roest M, de Graaf J, et al. Indications that paraoxonase-1 contributes to plasma high density lipoprotein levels in familial hypercholesterolemia. J Lipid Res 2005;46:445-51.

[43] van Himbergen TM, van Tits LJ, Hectors MP, de Graaf J, Roest M, Stalenhoef AF. Paraoxonase-1 and linoleic acid oxidation in familial hypercholesterolemia. Biochem Biophys Res Commun 2005;333:787-93.

[44] Mertens A, Holvoet P. Oxidized LDL and HDL: antagonists in atherothrombosis. Faseb J 2001;15:2073-84. 